\title{
Imbalance and dysfunction of transient receptor potential channels contribute to the pathogenesis of hypertension
}

\author{
LIU DaoYan*, XIONG ShiQiang \& ZHU ZhiMing \\ Center for Hypertension and Metabolic Diseases, Department of Hypertension and Endocrinology, Daping Hospital, Third Military Medical \\ University, Chongqing Institute of Hypertension, Chongqing 400042, China
}

Received May 5, 2014; accepted July 11, 2014

\begin{abstract}
Intracellular $\mathrm{Ca}^{2+}$ homeostasis is essential for vascular function and blood pressure regulation. Because of their unique roles in regulating intracellular $\mathrm{Ca}^{2+}$ concentration and vascular function, a novel class of non-selective cation channels, called transient receptor potential (TRP) channels, have emerged at the frontier of hypertension research. Based on their role in vasculature function regulation, TRP channels can be divided into two functional subtypes: one that participates in vasoconstriction and one that participates in vasodilatation. A functional imbalance of these two subtypes of TRP channels may disturb intracellular calcium $\left(\left[\mathrm{Ca}^{2+}\right] \mathrm{i}\right)$ homeostasis, and the consequent vascular dysfunction may contribute to the development of hypertension. The potential of these TRP channels as novel pharmacological targets for the treatment of human hypertension is of great interest.
\end{abstract}

TRP channels, $\mathrm{Ca}^{2+}$ homeostasis, vascular function, hypertension

Citation: Liu DY, Xiong SQ, Zhu ZM. Imbalance and dysfunction of transient receptor potential channels contribute to the pathogenesis of hypertension. Sci China Life Sci, 2014, 57: 818-825, doi: 10.1007/s11427-014-4713-3

Hypertension is a principal risk factor for atherosclerosis, stroke, myocardial infarction, heart failure, and end-stage renal failure and is emerging as an important global public-health challenge [1]. The pathogenesis of hypertension involves genetic and environmental factors. Several pathways are thought to elevate blood pressure, including increased sympathetic nerve activity, activation of the renin-angiotensin system, endothelial lesions, abnormal renal sodium handling, and vascular dysfunction [2]. Importantly, intracellular $\mathrm{Ca}^{2+}$ homeostasis is essential for vascular function and blood pressure regulation as well as hormone secretion. Disturbance of intracellular $\mathrm{Ca}^{2+}$ homeostasis has been reported in both experimental and human hypertension $[3,4]$.

Two sources are available to elevate the intracellular $\mathrm{Ca}^{2+}$ concentration $\left(\left[\mathrm{Ca}^{2+}\right] \mathrm{i}\right)$. In one process, the inosi-

*Corresponding author (email: daoyanliu@yahoo.com) tol-1,4,5-triphosphate $\left(\mathrm{IP}_{3}\right)$ receptor mediates $\mathrm{Ca}^{2+}$ release from the internal $\mathrm{Ca}^{2+}$ stores of the endoplasmic reticulum (ER). Store-operated $\mathrm{Ca}^{2+}$ channels (SOCs, or capacitative $\mathrm{Ca}^{2+}$ entry channels) are activated through $\mathrm{IP}_{3}$-induced $\mathrm{Ca}^{2+}$ release and consequently deplete $\mathrm{Ca}^{2+}$ from ER stores [5]. ER and sarcoplasmic reticulum (SR) stores are released through the stimulation of G-protein-coupled receptors, which activate phospholipase $\mathrm{C}$, consequently generating $\mathrm{IP}_{3}$ and activating the diacylglycerol (DAG) signal pathways. TRPCs (TRPC1-7), TRPC2, TRPC3, TRPC6 and TRPC7 have been reported to be activated by DAG [6-8]. Numaga et al. [9] established TRPC3 as a DAG-activated cation channel (DACCs) in B-cells. DAG-activated TRPC6 signals the membrane translocation and activation of PKC and thereby induces RhoA activation and endothelial contraction [10].

Another $\mathrm{Ca}^{2+}$ source is influx from the extracellular milieu through several types of ion channels, including 
$\mathrm{Na}^{+} / \mathrm{Ca}^{2+}$ exchanger, ligand-gated cation channels (LGCs), receptor-activated cation channels (RACs), and stretchactivated cation channels (SACs). Contractile VSMCs express $\mathrm{Ca}^{2+}$ transporters, including voltage-gated L-type $\mathrm{Ca}^{2+}$ channels (LTCCs) and sarco/endoplasmic reticulum $\mathrm{Ca}^{2+}$ ATPase type 2a (SERCA2a) pump, which maintain low resting cytosolic $\mathrm{Ca}^{2+}$ and allow dynamic changes of $\mathrm{Ca}^{2+}$ in the spatial and temporal domain, while non-contractile VSMCs have significantly reduced voltage dependence of $\mathrm{Ca}^{2+}$ entry [11]. In the past two decades, a novel family of nonselective cation channels called transient receptor potential (TRP) channels has been intensively investigated. Unlike voltage-gated ion channels, TRP channels lack a voltage-sensing moiety; they therefore function as voltage-independent, nonselective cation channels that are permeable to $\mathrm{Na}^{+}, \mathrm{K}^{+}, \mathrm{Cs}^{+}, \mathrm{Li}^{+}, \mathrm{Ca}^{2+}$, and $\mathrm{Mg}^{2+}$ [12]. TRP channels are researched in the fields as diverse as oncology, urology, dermatology, migraine, inflammation and pain. Among the TRPC, TRPV and TRPM subfamilies as well as TRPA1 appear to be involved in glioma, breast, gut, head and neck cancers to lung and prostate cancers [13]. Streng et al. [14] showed that hydrogen sulfide-sensitive TRPA1 ion channel was expressed in rat urinary bladder. The available evidence that identifies TRPA1 and TRPV1 contribute to migraine and cluster headache trigger [15,16], and TRPA1 activity impacts on cerebral circulation and pain sensitivity [17]. TRPA1 channels are activated by ROS, reactive nitrogen species (RNS) and other electrophiles, thus identifying the channel as a sensor of oxidative and nitrative stress generated at sites of inflammation or tissue injury [18]. Because of their unique roles in regulating the intracellular $\mathrm{Ca}^{2+}$ concentration and vascular function, the identification of mammalian TRP channels marked a new starting point in the molecular identification of $\mathrm{Ca}^{2+}$ entry pathways that contribute to the development of cardiovascular disease.

\section{Distribution and functions of TRP channels}

The TRP channels were named after the Drosophila melanogaster ion channel that is mutated in the trp gene, as first reported by Minke [19]. Twenty-eight members of the TRP channel superfamily have been identified in almost every tissue of mammals [20]. Based on their amino acid sequence homology, mammalian TRP channels can be divided into six subfamilies, including TRP canonical (TRPC; TRPC1-7), TRP vanilloid (TRPV; TRPV1-6), TRP melastatin (TRPM; TRPM1-8), TRP mucolipin (TRPML; TRPML1-3), TRP ankyrin (TRPA; TRPA1) and TRP polycystin (TRPP; TRPP2, TRPP3, TRPP5) [20]. In general, all seven members of TRPC [21-25]; TRPV1, -2, -4 [26-28]; all TRPM, except TRPM5 [27] and TRPP1 and -2 [29,30], have been reported to expressed in vascular endothelial cells (ECs) from various sources. TRP channels other than
TRPV5, TRPV6, and TRPM1 are found in arterial smooth muscle from different segments of the vasculature [31]. Based on their roles in regulating vasculature functioning, TRP channels can be divided into two functional subtypes: one that participates in vasoconstriction and one that participates in vasodilatation.

\section{TRP channels participate in vasoconstriction}

TRPC1 was the first cloned mammalian homologue of Drosophila trp [32]. Several studies have suggested that TRPC1 is a component of the store-operated $\mathrm{Ca}^{2+}$ entry pathway in both vascular smooth muscle cell (VSMC) and ECs. Over-expression of the human trpcl gene in rat pulmonary artery enhanced vasoconstriction via store depletion-mediated $\mathrm{Ca}^{2+}$ influx [33]. One study found that thapsigargin-stimulated store-operated current was reduced in TRPC1 siRNA- or TRPC1 antisense-expressing cells [34]. Ahmmed et al. [35] demonstrated that phosphorylation of TRPC1 via PKC alpha was an important determinant of store-operated $\mathrm{Ca}^{2+}$ entry in human ECs. Additionally, TRPC1 proteins confer PKC and phosphoinositol activation on native heteromeric TRPC1/C5 channels in vascular smooth muscle [36]. TRPC3 has been shown to be involved in the agonist-induced depolarization and vasoconstriction of arterial SMCs, and suppression of TRPC3 expression was found to significantly decrease the depolarization and constriction of intact cerebral arteries in response to UTP [37]. Xu et al. [38] found that sphingolipids and TRP channels are functionally linked in VSMCs and that the sphingolipids' metabolite, sphingosine-1-phosphate, activates TRPC5, thus controlling VSMC motility. TRPC6 has been suggested to have a major role in the regulation of myogenic tone [39]. The inhibition of TRPC6 has been found to decrease TRPC6 protein expression and greatly attenuate arterial smooth muscle depolarization and constriction caused by elevated pressure in intact cerebral arteries [39]. In another study, the isolated aortic rings and cerebral arteries of TRPC6-deficient mice showed an enhanced agonist-induced constriction [40]. Likewise, TRPC6-deficient mice showed a higher basal cation entry in VSMC, increased TRPC-carried cation currents, and more depolarized membrane potentials because of constitutively active TRPC3 channels [40]. These data implicate the concept of the formation of TRPC3/6 heteromeric complexes with a tightly receptor-operated TRPC6 subunit suppressing TRPC3 basal activity [41]. Furthermore, some multimerization data show that TRPC $3 / 6$ tetramers are formed in a heterologous expression system [42], in brain synaptosomes [43], and in polarized epithelial cells [44]. These findings may be compatible with the hypothesis that, in such heteromultimeric complexes, TRPC6 may suppress the basal activity of TRPC3, leading to a tightly receptor-regulated cation channel complex required for the physiological regu- 
lation of smooth muscle tone [40]. Recently, the studies indicate a critical role of TRPM4 in myogenic constriction of cerebral arteries. Pressure-induced SMC depolarization was attenuated in isolated cerebral arteries treated with TRPM4 antisense oligodeoxynucleotides. Activation of TRPM4-dependent currents contributed to myogenic vasoconstriction of cerebral arteries [45]. In vivo suppression of TRPM4 decreases cerebral artery myogenic constrictions and impairs auto-regulation, thus implicating TRPM4 channels and myogenic constriction as major contributors to cerebral blood flow regulation in the living animal [46]. Narayanan et al. [47] demonstrated that TRPP2 was expressed in SMCs of resistance-size cerebral arteries and contributed to the myogenic response. One member of TRPV subfamily, TRPV2, was found to be expressed in mouse aortic, mesenteric and basilar arterial myocytes and could be activated by membrane stretch and hypotonic stimulation [48]. Whether TRPV2 is involved in the generation of myogenic tone remains to be elucidated.

\section{TRP channels contribute to vasodilatation}

Some TRP channels are present in both vascular endothelial and VSMCs, and their role in the regulation of local vascular tone can be quite different. The synthesis and release of endothelium-derived relaxing factors (EDRFs) are linked to an increase in cytosolic $\mathrm{Ca}^{2+}$ concentration, EDRFs produced by endothelial cells not only control vascular tone, but also have multiple beneficial effects including the modulation of platelet aggregation, the inhibition of leucocyte adhesion, and the control of VSMC proliferation [49,50]. One of the most important functions of the endothelium is to modulate vascular tone. TRPC1/TRPC3 channels were found to be present in freshly isolated VSMCs, were inhibited by the NO/cGMP/PKG pathway and contributed to NO-induced vasodilatation [51]. TRPC3 was also detected in human and rodents' vascular ECs and facilitated endothelium-derived hyperpolarization-mediated resistance artery vasodilator activity $[52,53]$. TRPC4 proteins have also been identified as indispensable components of storeoperated $\mathrm{Ca}^{2+}$ channels in mouse aortic ECs, as agonist-activated $\mathrm{Ca}^{2+}$ entry into TRPC4-deficient ECs was found to be drastically decreased, leading to a dramatically impaired endothelium-dependent relaxation [54]. TRPV1 is abundant in the endothelium. In freshly isolated rodent mesenteric arteries, activation of TPRV1 by its agonist capsaicin elicited an acute release of NO from ECs and vasodilatation, which was inhibited by the TRPV1 antagonists and was absent from arteries of TRPV1-deficient mice [26]. TRPV4 channels in the vascular ECs and SMCs are critically involved in the vasodilatation of mesenteric arteries in response to endothelial-derived factors [28]. One study found that the genetically encoded loss-of-function of trpv4 resulted in a loss of shear stress-induced vasodilatation, a response pattern largely dependent on endothelial TRPV4 expression [55]. In a previous study, we demonstrated that TRPM8 activation, by its agonist menthol, antagonized vasoconstriction by inhibiting $\mathrm{Ca}^{2+}$ signaling-mediated RhoA/ROCK activation in the vasculature [56]. TRPA1 channels are present in the endothelium and mediated vasodilatation via endothelium-dependent and independent mechanisms $[57,58]$. The role of TRPA1 in the cardiovascular system remains elusive (Table 1).

\section{TRP channel subtype $C$ dysfunction pro- motes the development of hypertension}

Abnormal expression and dysfunction of TRP channels have been reported in both hypertensive patients and animal models. Alterations of cellular cation influx (e.g., $\mathrm{Ca}^{2+}$ or $\mathrm{Na}^{+}$influx), in peripheral blood cells or VSMCs, have frequently been described in primary hypertension. The recruitment of circulating peripheral monocytes, their activation and their differentiation into tissue macrophages play an important role in the early stages of atherosclerotic lesion formation [59]. Thilo et al. [60] observed an approximately 8 -fold increase of TRPC3 transcripts in monocytes from patients with essential hypertension compared to normotensive control subjects, demonstrating a significant correlation between TRPC3 transcripts and systolic blood pressure, expression of IL-1beta, and TNF-alpha. In addition, increased TRPC3 and TRPC5 expression in monocytes of patients with essential hypertension, a subsequent storeoperated $\mathrm{Ca}^{2+}$ influx, and increased 1-oleoyl-2-acetyl-snglycerol-induced cation influx in monocytes of patients with essential hypertension were observed [61]. Liu et al. [1] compared the expression level and function of TRPCs between essential hypertensive patients and normotensive control subjects. They demonstrated increased TRPC3 and TRPC5 protein expression and an increase in the gadolinium/calcium-influx ratio via TRPCs in monocytes of patients with essential hypertension [1]. Furthermore, they demonstrated an increase in TRPC3 expression in VSMCs and aortic tissues and TRPC3-related $\mathrm{Ca}^{2+}$ influx in VSMCs from spontaneously hypertensive rats (SHRs), which was associated with enhanced contraction in vasculature from SHRs compared with the normotensive WKY rats [4]. Thus, increased TRPC3 channel protein expression in the monocytes and vasculature is important for elevated blood pressure. Increased rhythmicity in hypertensive arterial smooth muscle was also found to be related to TRPCs [62]. Another study found that norepinephrine-induced vasomotion and $\mathrm{Ca}^{2+}$ influx were increased in mesenteric arterioles from SHRs, consistent with up-regulated expression of TRPC1, TRPC3 and TRPC5 [62]. TRPC6 knockout mice have shown greatly enhanced expression of TRPC3 and enhanced agonist-induced arterial vasoconstriction, consequently exhibiting increased blood pressure [40]. This find- 
ing suggested that increased TRPC3 expression relative to that of TRPC6 may predispose mice to hypertension [63]. The expression level of TRPC6 and the $\mathrm{Ca}^{2+}$ influx currents it mediated have been found to be increased in the mesenteric arteries of deoxycorticosterone acetate-salt hypertensive rats [64]. These studies suggest that dysfunction of TRP channel subtype $C$ contributes to altered vascular reactivity and promotes the development of hypertension.

\section{TRP channel subtypes $M$ and $V$ have anti- hypertensive effects}

Some TRP channels contribute to vasodilatation and may attenuate hypertension. Intracellular magnesium depletion has been implicated in the vascular dysfunction of hypertension. Considering that TRPM7 is $\mathrm{Mg}^{2+}$-permeant channel responsible for transcellular $\mathrm{Mg}^{2+}$ transport. Altered cellular $\mathrm{Mg}^{2+}$ homeostasis and abnormal VSMC function in hypertension may be related to defective TRPM7 expression/ activity [65,66]. Touyz et al. [67] demonstrated that TRPM7 was present and functionally active in human, mouse and rat VSMCs. Furthermore, they found that TRPM6 was unaltered in SHR, but expression of TRPM7 was blunted. This was associated with attenuated annexin-1 translocation and decreased VSMC $\left[\mathrm{Mg}^{2+}\right] \mathrm{i}$ in SHR [68]. TRPM8 is involved in the regulation of vascular tone, and the down-regulation of TRPM8 may contribute to enhanced vasoreactivity in pulmonary hypertension [69]. TRPM8 activation by men- thol was found to attenuate vasoconstriction via RhoA/ ROCK pathway inhibition [56]. Chronic dietary menthol blunted mesenteric arterial constriction and lowered blood pressure in both SHRs and pre-hypertensive individuals [56]. Flow-mediated dilatation in pre-hyperten- sive individuals was also improved by chronic menthol administration [56]. Growing evidence suggests that TRPV1 channels play multiple important roles in hypertension via several different mechanisms. TRPV1 activation exerts antihypertension effects by stimulating the release of calcitonin gene-related peptide (CGRP) from capsaicin-sensitive sensory nerves and NO from ECs [26,70]. In vivo, plasma concentration of CGRP rises transiently after acute administration of capsaicin in adult rats, accompanied by a decrease in blood pressure [71]. In a previous study, we showed that the TRPV1 agonist capsaicin acutely relaxed mesenteric arteries through at least two mechanisms: a direct action on ECs, which was NO dependent and L-NAME sensitive, and the release of CGRP, which activated an L-NAME-insensitive pathway, but to a lesser degree [26]. Activation of TRPV1 enhanced endothelium-dependent relaxation in wild-type mice, an effect absent in TRPV1- deficient mice [26]. In another study, long-term stimulation of TRPV1 by dietary capsaicin attenuated hypertension in SHRs [26]. TRPV1 channels have also been proposed to be involved in the pathogenesis of salt-induced hypertension. TRPV1 expression in mesenteric resistance arteries, the renal cortex and medulla, CGRP levels in dorsal root ganglia, and CGRP-positive sensory nerve density in mesenteric resistance arteries were significantly up-regulated during

Table 1 TRP channels in vascular function regulation and hypertension

\begin{tabular}{|c|c|c|c|}
\hline TRP channels & Distribution & Proposed roles & Main references \\
\hline $\begin{array}{c}\text { TRPC1 } \\
\text { TRPC1/TRPC3 }\end{array}$ & $\begin{array}{l}\text { VSMC } \\
\text { VSMC }\end{array}$ & $\begin{array}{l}\text { A component of store-operated } \mathrm{Ca}^{2+} \text { entry pathway, contributing to enhanced vasoconstriction. } \\
\text { 1. Inhibited by the NO/cGMP/PKG pathway, contributes to NO-induced vasodilatation. } \\
\text { 2. Increased expression and contribution to increased vasomotion in hypertension }\end{array}$ & $\begin{array}{l}{[33-35]} \\
{[51]} \\
{[62]}\end{array}$ \\
\hline TRPC3 & $\begin{array}{l}\text { VSMC } \\
\text { EC }\end{array}$ & $\begin{array}{l}\text { 1. Involved in UTP-mediated depolarization and vasoconstriction. } \\
\text { 2. Facilitates endothelium-derived hyperpolarization-mediated resistance artery vasodilatation. }\end{array}$ & $\begin{array}{c}{[37]} \\
{[52,53]}\end{array}$ \\
\hline TRPC3, TRPC5 & $\begin{array}{l}\text { VSMC } \\
\text { monocyte }\end{array}$ & $\begin{array}{l}\text { Increased expression and } \mathrm{Ca}^{2+} \text { influx in VSMC and monocytes from hypertensive animals and } \\
\text { patients. }\end{array}$ & {$[1,60-62]$} \\
\hline TRPC4 & $\mathrm{EC}$ & Functions as $\mathrm{Ca}^{2+}$ conducting, non-selective cation channel and contributes to vasodilatation & [54] \\
\hline TRPC5 & VSMC & Activation of TRPC5 by sphingosine-1-phospate, controlling VSMC motility. & {$[38]$} \\
\hline TRPC6 & VSMC & $\begin{array}{l}\text { 1. Regulation of myogenic tone. } \\
\text { 2. TRPC6-deficient mice show elevated blood pressure and enhanced vasoconstriction. } \\
\text { 3. Implicated in deoxycorticosterone acetate-salt-induced hypertension. } \\
\text { 1. Involved in endothelium-dependent vasodilatation. } \\
\text { 2. TRPV1 activation prevents hypertension. } \\
\text { 3. Related to salt-induced increase in blood pressure. } \\
\text { 4. Regulation of salt-intake behaviors that are associated with salt-sensitive hypertension. }\end{array}$ & $\begin{array}{c}{[39]} \\
{[40]} \\
{[64]} \\
{[26,70-74]}\end{array}$ \\
\hline TRPV2 & VSMC & Implicated in mechano-sensitive membrane depolarization and hypotonic stimulation & [48] \\
\hline TRPV4 & VSMC, EC & $\begin{array}{l}\text { 1. TRPV4 activation in the EC and VSMC promotes vasodilatation. } \\
\text { 2. Enhanced TRPV4 expression may counterbalance salt-induced increases in blood pressure. }\end{array}$ & $\begin{array}{l}{[28,55]} \\
{[75]}\end{array}$ \\
\hline TRPM4 & VSMC & Contribution to pressure-induced vasoconstriction and control of cerebral artery myogenic tone. & {$[45,46]$} \\
\hline TRPM7 & VSMC & $\begin{array}{l}\text { Defective TRPM7 expression/activity contribute to altered cellular } \mathrm{Mg}^{2+} \text { homeostasis and ab- } \\
\text { normal VSMC function in SHRs. }\end{array}$ & [65-68] \\
\hline TRPM8 & VSMC & $\begin{array}{l}\text { 1. Attenuates vasoconstriction via RhoA/ROCK pathway and lowers blood pressure. } \\
\text { 2. Reduced TRPM8 may contribute to the enhanced vasoreactivity in } \mathrm{PH} \text {. }\end{array}$ & $\begin{array}{l}{[56]} \\
{[69]}\end{array}$ \\
\hline TRPA1 & $\mathrm{EC}$ & Mediates vasodilatation via endothelium-dependent and independent mechanisms. & {$[57,58]$} \\
\hline TRPP2 & VSMC & Contributes to the myogenic response of resistance-size cerebral arteries & [47] \\
\hline
\end{tabular}


high-salt intake in Dahl salt-resistant rats, which acted to prevent salt-induced increases in blood pressure [72]. In contrast, TRPV1 expression and function was impaired in Dahl salt-sensitive rats, which rendered Dahl salt-sensitive rats to salt load in terms of blood pressure regulation [72]. Hao et al. [73] showed that endothelium-dependent relaxation in mesenteric resistance arteries was impaired in mice fed on high-salt diet, which was associated with increased superoxide anion generation and reduced NO levels. Activation of TRPV1 by dietary capsaicin was found to reduce the high-salt-intake induced endothelial dysfunction, and nocturnal hypertension, in part by preventing the vascular oxidative stress [73]. TRPV1 may also mediate a general aversive response to salt, indicating a role for TRPV1 in regulating salt intake behaviors, which are tightly related to the development of salt-sensitive hypertension [74]. TRPV4 channels are also critically associated with salt-sensitive hypertension. High-salt intake may up-regulate the expressio $\mathrm{n}$ and function of TRPV4 to counterbalance salt-induced increases in blood pressure in a salt-resistant strain of rats [75]. WNK4 is a member of WNK kinase family and regulates the expression of TRPV4. Functional regulation of TRPV4 by WNK4 may influence systemic $\mathrm{Ca}^{2+}$ balance and contribute to vascular function and blood pressure regulation. Mutations in the gene encoding WNK4 have been linked to monogenic hypertension [76]. These findings highlight a promising role for TRP channel subtype $\mathrm{M}$ and $\mathrm{V}$ in the treatment of hypertension.
Functional equilibrium between different TRP channels subtypes plays a critical role in maintaining vascular physiological function and normal blood pressure. If this delicate balance is broken, it may cause vascular dysfunction and lead to high blood pressure. This hypothesis was supported by our previous study, which revealed enhanced TRPC $3 / 5$ mediated vasoconstriction and impaired TRPV1/TRPM8induced vasodilatation in hypertension $[4,26,56,62,77]$, in parallel with similar findings from other groups. Thus, we propose an imbalance of TRP channel functions as a new etiology for hypertension (Figure 1).

\section{Perspectives and conclusion}

Elucidating the roles of TRP channels, acting both singly and as a network, in the physiology and pathology of vascular function and blood pressure regulation is of prime importance. To achieve this goal, new strategies, including systems biology, engineering of novel animal models related to TRP channels, optic-genetics and channelomics, may be helpful. Currently, the lack of specific TRP channel subtype $\mathrm{C}$ modulators restricts their application in the management of hypertension. There is an urgent need for novel modulators of TRP channels. Furthermore, translational research on TRP channels should be accelerated. New research findings should be taken from the bench to the bedside. In conclusion, TRP channels exert multiple functions

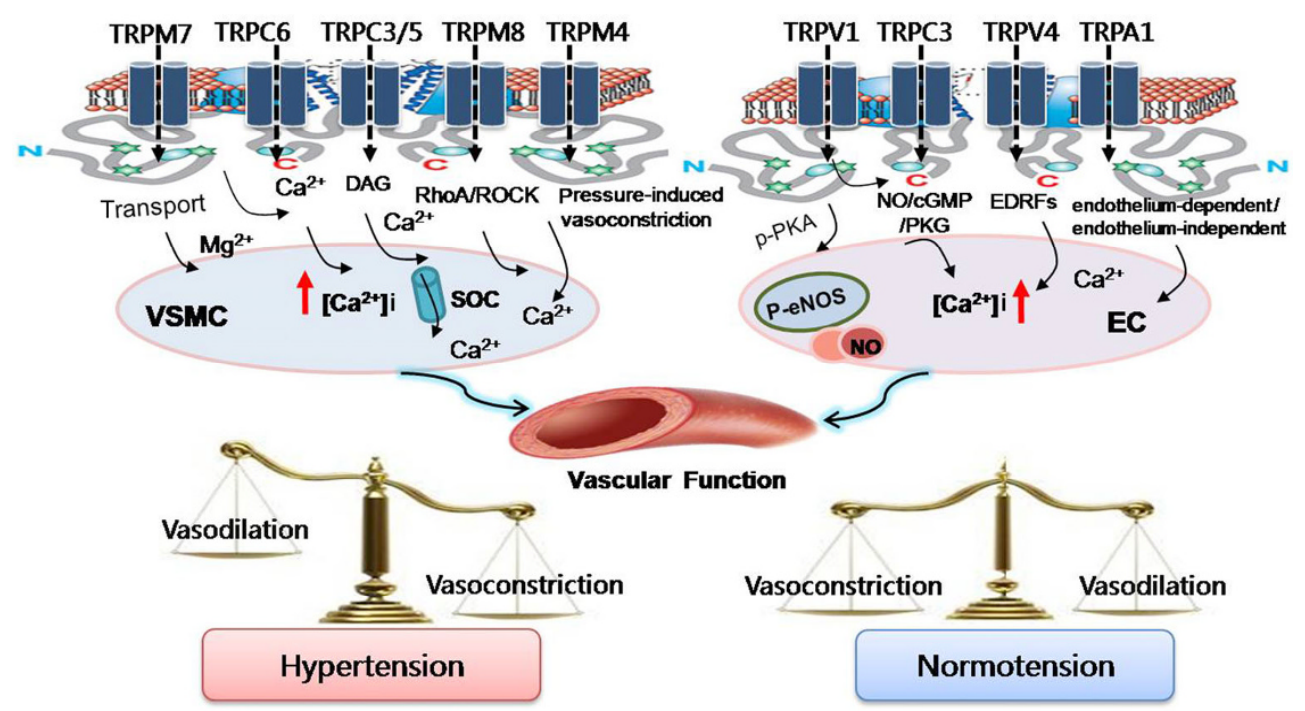

Figure 1 (color online) Functional balance of TRP channels in the regulation of vascular function and blood pressure. Based on their role in vasculature function regulation, TRP channels can be divided into two functional subtypes: one that participates in vasoconstriction and one that participates in vasodilatation. Activation of TRPC3/5 expression results in an increase in VSMC $\left[\mathrm{Ca}^{2+}\right] \mathrm{i}$ via SOC- and DAG-mediated Ca ${ }^{2+}$ influx. Ang II and norepinephrine up-regulate TRPC3/5 expression and lead to $\mathrm{Ca}^{2+}$ influx and vasoconstriction as well as increased blood pressure. TRPC6-deficient mice show elevated blood pressure and enhanced vasoconstriction. TRPM4 is associated with pressure-induced vasoconstriction. Reduced expression of TRPM7 contributes to vasoconstriction in SHRs. Activation of TRPM8 by menthol inhibits $\mathrm{Ca}^{2+}$ signaling-mediated RhoA/ROCK activation in the vasculature and lowers blood pressure. TRPV4 is involved in temperature dependent and shear stress-induced vasodilatation in the EC. TRPC 3 facilitates endothelium-derived hyperpolarization-mediated resistance artery vasodilatation. TRPA1 via endothelium-dependent and independent contributes to vasodilatation. Activation of TRPV1 by capsaicin increases the pPKA and eNOS in ECs, thereby leading to enhanced vasodilatation and lower blood pressure. 
in the physiological regulation of vascular function and blood pressure. An imbalance in TRP channels' multiple functions may impair vascular function and lead to high blood pressure.

1 Liu D, Scholze A, Zhu Z, Krueger K, Thilo F, Burkert A, Streffer K, Holz S, Harteneck C, Zidek W, Tepel M. Transient receptor potential channels in essential hypertension. J Hypertens, 2006, 24: 1105-1114

2 Takahashi H, Yoshika M, Komiyama Y, Nishimura M. The central mechanism underlying hypertension: a review of the roles of sodium ions, epithelial sodium channels, the renin-angiotensin-aldosterone system, oxidative stress and endogenous digitalis in the brain. Hypertens Res, 2011, 34: 1147-1160

3 Thilo F, Loddenkemper C, Berg E, Zidek W, Tepel M. Increased TRPC3 expression in vascular endothelium of patients with malignant hypertension. Mod Pathol, 2009, 22: 426-430

4 Liu D, Yang D, He H, Chen X, Cao T, Feng X, Ma L, Luo Z, Wang L, Yan Z, Zhu Z, Tepel M. Increased transient receptor potential canonical type 3 channels in vasculature from hypertensive rats. Hypertension, 2009, 53: 70-76

5 Putney JW Jr. Capacitative calcium entry revisited. Cell Calc, 1990, 11: 611-624

6 Hofmann T, Obukhov AG, Schaefer M, Harteneck C, Gudermann T, Schultz G. Direct activation of human TRPC6 and TRPC3 channels by diacylglycerol. Nature, 1999, 397: 259-263

7 Okada T, Inoue R, Yamazaki K, Maeda A, Kurosaki T, Yamakuni T, Tanaka I, Shimizu S, Ikenaka K, Imoto K, Mori Y. Molecular and functional characterization of a novel mouse transient receptor potential protein homologue TRP7. $\mathrm{Ca}(2+)$-permeable cation channel that is constitutively activated and enhanced by stimulation of $\mathrm{G}$ protein-coupled receptor. J Biol Chem, 1999, 274: 27359-27370

8 Lucas P, Ukhanov K, Leinders-Zufall T, Zufall F. A diacylglycerolgated cation channel in vomeronasal neuron dendrites is impaired in TRPC2 mutant mice: mechanism of pheromone transduction. Neuron, 2003, 40: 551-561

9 Numaga T, Nishida M, Kiyonaka S, Kato K, Katano M, Mori E, Kurosaki T, Inoue R, Hikida M, Putney JW Jr, Mori Y. $\mathrm{Ca}^{2+}$ influx and protein scaffolding via TRPC3 sustain PKC beta and ERK activation in B cells. J Cell Sci, 2010, 123: 927-938

10 Singh I, Knezevic N, Ahmmed GU, Kini V, Malik AB, Mehta D. Galphaq-TRPC6-mediated $\mathrm{Ca}^{2+}$ entry induces RhoA activation and resultant endothelial cell shape change in response to thrombin. J Biol Chem, 2007, 282: 7833-7843

11 Matchkov VV, Kudryavtseva O, Aalkjaer C. Intracellular $\mathrm{Ca}^{2+}$ signalling and phenotype of vascular smooth muscle cells. Basic Clin Pharmacol, 2012, 110: 42-48

12 Nilius B, Owsianik G, Voets T, Peters JA. Transient receptor potential cation channels in disease. Physiol Rev, 2007, 87: 165-217

13 Holzer P, Izzo AA. The pharmacology of TRP channels. British J Pharmacol, 2014, 171: 2469-2473

14 Streng T, Axelsson HE, Hedlund P, Andersson DA, Jordt SE, Bevan $\mathrm{S}$, Andersson KE, Högestätt ED, Zygmunt PM. Distribution and function of the hydrogen sulfide-sensitive TRPA1 ion channel in rat urinary bladder. Eur Urol, 2008, 53: 391-399

15 Lima AM, Sapienza GB, Giraud VD, Fragoso YD. Odors as triggering and worsening factors for migraine in men. Arq Neuro-Psiquiat, 2011, 69: 324-327

16 Rozen TD. Cluster headache as the result of secondhand cigarette smoke exposure during childhood. Headache, 2010, 50: 130-132

17 Earley S. TRPA1 channels in the vasculature. British J Pharmacol, 2012, 167: 13-22

18 Benemei S, Fusi C, Trevisan G, Geppetti P. The TRPA1 channel in migraine mechanism and treatment. British J Pharmacol, 2014, 171: 2552-2567

19 Minke B. Drosophila mutant with a transducer defect. Biophys Struct Mech, 1977, 3: 59-64
20 Nilius B, Owsianik G. Transient receptor potential channelopathies. Pflugers Archiv, 2010, 460: 437-450

21 Moore TM, Brough GH, Babal P, Kelly JJ, Li M, Stevens T. Store-operated calcium entry promotes shape change in pulmonary endothelial cells expressing Trp1. Am J Physiol, 1998, 275: L574-582

22 Paria BC, Vogel SM, Ahmmed GU, Alamgir S, Shroff J, Malik AB, Tiruppathi C. Tumor necrosis factor-alpha-induced TRPC1 expression amplifies store-operated $\mathrm{Ca}^{2+}$ influx and endothelial permeability. Am J Physiol Lung Cell Mol Physiol, 2004, 287: L1303-1313

23 McDaniel SS, Platoshyn O, Wang J, Yu Y, Sweeney M, Krick S, Rubin LJ, Yuan JX. Capacitative $\mathrm{Ca}(2+)$ entry in agonist-induced pulmonary vasoconstriction. Am J Physiol Lung Cell Mol Physiol, 2001, 280: L870-880

24 Yip H, Chan WY, Leung PC, Kwan HY, Liu C, Huang Y, Michel V, Yew DT, Yao X. Expression of TRPC homologs in endothelial cells and smooth muscle layers of human arteries. Histochem Cell Biol, 2004, 122: 553-561

25 Groschner K, Hingel S, Lintschinger B, Balzer M, Romanin C, Zhu $\mathrm{X}$, Schreibmayer W. Trp proteins form store-operated cation channels in human vascular endothelial cells. FEBS Lett, 1998, 437: 101-106

26 Yang D, Luo Z, Ma S, Wong WT, Ma L, Zhong J, He H, Zhao Z, Cao T, Yan Z, Liu D, Arendshorst WJ, Huang Y, Tepel M, Zhu Z. Activation of TRPV1 by dietary capsaicin improves endotheliumdependent vasorelaxation and prevents hypertension. Cell Metab, 2010, 12: 130-141

27 Fantozzi I, Zhang S, Platoshyn O, Remillard CV, Cowling RT, Yuan JX. Hypoxia increases AP-1 binding activity by enhancing capacitative $\mathrm{Ca}^{2+}$ entry in human pulmonary artery endothelial cells. Am J Physiol Lung Cell Mol Physiol, 2003, 285: L1233-1245

28 Earley S, Pauyo T, Drapp R, Tavares MJ, Liedtke W, Brayden JE. TRPV4-dependent dilation of peripheral resistance arteries influences arterial pressure. Am J Physiol Heart Circ Physiol, 2009, 297: H1096-1102

29 Ong AC, Ward CJ, Butler RJ, Biddolph S, Bowker C, Torra R, Pei Y, Harris PC. Coordinate expression of the autosomal dominant polycystic kidney disease proteins, polycystin-2 and polycystin-1, in normal and cystic tissue. Am J Pathol, 1999, 154: 1721-1729

30 Ibraghimov-Beskrovnaya O, Dackowski WR, Foggensteiner L, Coleman N, Thiru S, Petry LR, Burn TC, Connors TD, Van Raay T, Bradley J, Qian F, Onuchic LF, Watnick TJ, Piontek K, Hakim RM, Landes GM, Germino GG, Sandford R, Klinger KW. Polycystin: in vitro synthesis, in vivo tissue expression, and subcellular localization identifies a large membrane-associated protein. Proc Natl Acad Sci USA, 1997, 94: 6397-6402

31 Earley S. Vanilloid and melastatin transient receptor potential channels in vascular smooth muscle. Microcirculation, 2010, 17: 237-249

32 Zhu X, Chu PB, Peyton M, Birnbaumer L. Molecular cloning of a widely expressed human homologue for the Drosophila trp gene. FEBS Lett, 1995, 373: 193-198

33 Kunichika N, Yu Y, Remillard CV, Platoshyn O, Zhang S, Yuan JX. Overexpression of TRPC1 enhances pulmonary vasoconstriction induced by capacitative $\mathrm{Ca}^{2+}$ entry. Am J Physiol Lung Cell Mol Physiol, 2004, 287: L962-969

34 Brueggemann LI, Markun DR, Henderson KK, Cribbs LL, Byron KL. Pharmacological and electrophysiological characterization of store-operated currents and capacitative $\mathrm{Ca}^{2+}$ entry in vascular smooth muscle cells. J Pharmacol Exp Ther, 2006, 317: 488-499

35 Ahmmed GU, Mehta D, Vogel S, Holinstat M, Paria BC, Tiruppathi C, Malik AB. Protein kinase Calpha phosphorylates the TRPC1 channel and regulates store-operated $\mathrm{Ca}^{2+}$ entry in endothelial cells. J Biol Chem, 2004, 279: 20941-20949

36 Shi J, Ju M, Abramowitz J, Large WA, Birnbaumer L, Albert AP. TRPC1 proteins confer PKC and phosphoinositol activation on native heteromeric TRPC1/C5 channels in vascular smooth muscle: comparative study of wild-type and TRPC1(-/-) mice. FASEB J, 2012, 26: 409-419 
37 Reading SA, Earley S, Waldron BJ, Welsh DG, Brayden JE. TRPC3 mediates pyrimidine receptor-induced depolarization of cerebral arteries. Am J Physiol-Heart C, 2005, 288: H2055-2061

38 Xu SZ, Muraki K, Zeng F, Li J, Sukumar P, Shah S, Dedman AM, Flemming PK, McHugh D, Naylor J, Cheong A, Bateson AN, Munsch CM, Porter KE, Beech DJ. A sphingosine-1-phosphateactivated calcium channel controlling vascular smooth muscle cell motility. Circ Res, 2006, 98: 1381-1389

39 Welsh DG, Morielli AD, Nelson MT, Brayden JE. Transient receptor potential channels regulate myogenic tone of resistance arteries. Circ Res, 2002, 90: 248-250

40 Dietrich A, Schnitzler MMY, Gollasch M, Gross V, Storch U, Dubrovska G, Obst M, Yildirim E, Salanova B, Kalwa H, Essin K, Pinkenburg O, Luft FC, Gudermann T, Birnbaumer L. Increased vascular smooth muscle contractility in TRPC6(-/-) mice. Mol Cell Biol, 2005, 25: 6980-6989

41 Dietrich A, Schnitzler MMY, Emmel J, Kalwa H, Hofmann T, Gudermann T. N-linked protein glycosylation is a major determinant for basal TRPC3 and TRPC6 channel activity. J Biol Chem, 2003, 278: 47842-47852

42 Hofmann T, Schaefer M, Schultz G, Gudermann T. Subunit composition of mammalian transient receptor potential channels in living cells. Proc Natl Acad Sci USA, 2002, 99: 7461-7466

43 Goel M, Sinkins WG, Schilling WP. Selective association of TRPC channel subunits in rat brain synaptosomes. J Biol Chem, 2002, 277: 48303-48310

44 Bandyopadhyay BC, Swaim WD, Liu XB, Redman RS, Patterson RL, Ambudkar IS. Apical localization of a functional TRPC3/TRPC6$\mathrm{Ca}^{2+}$-signaling complex in polarized epithelial cells-role in apical $\mathrm{Ca}^{2+}$ influx. J Biol Chem, 2005, 280: 12908-12916

45 Earley S, Waldron BJ, Brayden JE. Critical role for transient receptor potential channel TRPM4 in myogenic constriction of cerebral arteries. Circ Res, 2004, 95: 922-929

46 Reading SA, Brayden JE. Central role of TRPM4 channels in cerebral blood flow regulation. Stroke, 2007, 38: 2322-2328

47 Narayanan D, Bulley S, Leo MD, Burris SK, Gabrick KS, Boop FA, Jaggar JH. Smooth muscle cell transient receptor potential polycystin-2 (TRPP2) channels contribute to the myogenic response in cerebral arteries. J Physiol, 2013, 591: 5031-5046

48 Muraki K, Iwata Y, Katanosaka Y, Ito T, Ohya S, Shigekawa M, Imaizumi Y. TRPV2 is a component of osmotically sensitive cation channels in murine aortic myocytes. Circ Res, 2003, 93: 829-838

49 Schmidt HH, Pollock JS, Nakane M, Forstermann U, Murad F. $\mathrm{Ca}^{2+} /$ calmodulin-regulated nitric oxide synthases. Cell Calc, 1992, 13: 427-434

50 Lantoine F, Iouzalen L, Devynck MA, Millanvoye-Van Brussel E, David-Dufilho M. Nitric oxide production in human endothelial cells stimulated by histamine requires $\mathrm{Ca}^{2+}$ influx. Biochem J, 1998, 330: 695-699

51 Chen J, Crossland RF, Noorani MM, Marrelli SP. Inhibition of TRPC1/TRPC3 by PKG contributes to NO-mediated vasorelaxation. Am J Physiol Heart Circ Physiol, 2009, 297: H417-424

52 Smedlund K, Vazquez G. Involvement of native TRPC3 proteins in ATP-dependent expression of VCAM-1 and monocyte adherence in coronary artery endothelial cells. Arterioscler Thromb Vasc Biol, 2008, 28: 2049-2055

53 Senadheera S, Kim Y, Grayson TH, Toemoe S, Kochukov MY, Abramowitz J, Housley GD, Bertrand RL, Chadha PS, Bertrand PP, Murphy TV, Tare M, Birnbaumer L, Marrelli SP, Sandow SL. Transient receptor potential canonical type 3 channels facilitate endothelium-derived hyperpolarization-mediated resistance artery vasodilator activity. Cardiovasc Res, 2012, 95: 439-447

54 Freichel M, Suh SH, Pfeifer A, Schweig U, Trost C, Weissgerber P, Biel M, Philipp S, Freise D, Droogmans G, Hofmann F, Flockerzi V, Nilius B. Lack of an endothelial store-operated $\mathrm{Ca}^{2+}$ current impairs agonist-dependent vasorelaxation in $\mathrm{TRP}^{-/-}$mice. Nat Cell Biol, 2001, 3: 121-127

55 Hartmannsgruber V, Heyken WT, Kacik M, Kaistha A, Grgic I,
Harteneck C, Liedtke W, Hoyer J, Köhler R. Arterial response to shear stress critically depends on endothelial TRPV4 expression. PLoS ONE, 2007, 2: e827

56 Sun J, Yang T, Wang P, Ma S, Zhu Z, Pu Y, Li L, Zhao Y, Xiong S, Liu D, Zhu Z. Activation of cold-sensing transient receptor potential melastatin subtype 8 antagonizes vasoconstriction and hypertension through attenuating RhoA/Rho kinase pathway. Hypertension, 2014, 63: 1354-1363

57 Pozsgai G, Bodkin JV, Graepel R, Bevan S, Andersson DA, Brain SD. Evidence for the pathophysiological relevance of TRPA1 receptors in the cardiovascular system in vivo. Cardiovasc Res, 2010, 87: 760-768

58 Earley S, Gonzales AL, Crnich R. Endothelium-dependent cerebral artery dilation mediated by TRPA 1 and $\mathrm{Ca}^{2+}$-Activated $\mathrm{K}^{+}$channels. Circ Res, 2009, 104: 987-994

59 Lusis AJ. Atherosclerosis. Nature, 2000, 407: 233-241

60 Thilo F, Scholze A, Liu DY, Zidek W, Tepel M. Association of transient receptor potential canonical type 3 (TRPC3) channel transcripts with proinflammatory cytokines. Arch Biochem Biophys, 2008, 471: 57-62

61 Liu DY, Thilo F, Scholze A, Wittstock A, Zhao ZG, Harteneck C, Zidek W, Zhu ZM, Tepel M. Increased store-operated and 1-oleoyl-2-acetyl-sn-glycerol-induced calcium influx in monocytes is mediated by transient receptor potential canonical channels in human essential hypertension. J Hypertens, 2007, 25: 799-808

62 Chen X, Yang D, Ma S, He H, Luo Z, Feng X, Cao T, Ma L, Yan Z, Liu D, Tepel M, Zhu Z. Increased rhythmicity in hypertensive arterial smooth muscle is linked to transient receptor potential canonical channels. J Cell Mol Med, 2010, 14: 2483-2494

63 Liu D, Zhu Z, Tepel M. The role of transient receptor potential channels in metabolic syndrome. Hypertens Res, 2008, 31: 1989-1995

64 Bae YM, Kim A, Lee YJ, Lim W, Noh YH, Kim EJ, Kim J, Kim TK, Park SW, Kim B, Cho SI, Kim DK, Ho WK. Enhancement of receptor-operated cation current and TRPC6 expression in arterial smooth muscle cells of deoxycorticosterone acetate-salt hypertensive rats. J Hypertens, 2007, 25: 809-817

65 Hanano T, Hara Y, Shi J, Morita H, Umebayashi C, Mori E, Sumimoto H, Ito Y, Mori Y, Inoue R. Involvement of TRPM7 in cell growth as a spontaneously activated $\mathrm{Ca}^{2+}$ entry pathway in human retinoblastoma cells. J Pharmacol Sci, 2004, 95: 403-419

66 Schmitz C, Perraud AL, Johnson CO, Inabe K, Smith MK, Penner R, Kurosaki T, Fleig A, Scharenberg AM. Regulation of vertebrate cellular $\mathrm{Mg}^{2+}$ homeostasis by TRPM7. Cell, 2003, 114: 191-200

67 He Y, Yao GY, Savoia C, Touyz RM. Transient receptor potential melastatin 7 ion channels regulate magnesium homeostasis in vascular smooth muscle cells - role of angiotensin II. Circ Res, 2005, 96: 207-215

68 Touyz RM, He Y, Montezano ACI, Yao G, Chubanov V, Gudermann T, Callera GE. Differential regulation of transient receptor potential melastatin 6 and 7 cation channels by ANG II in vascular smooth muscle cells from spontaneously hypertensive rats. Am J Physiol Regul Integr Comp Physiol, 2006, 290: R73-78

69 Liu XR, Liu Q, Chen GY, Hu Y, Sham JSK, Lin MJ. Down-regulation of TRPM8 in pulmonary arteries of pulmonary hypertensive rats. Cell Physiol Biochem, 2013, 31: 892-904

70 Jansen I, Alafaci C, Uddman R, Edvinsson L. Evidence that calcitonin gene-related peptide contributes to the capsaicin-induced relaxation of guinea pig cerebral arteries. Regul pept, 1990, 31: 167-178

71 Peng J, Li YJ. The vanilloid receptor TRPV1: role in cardiovascular and gastrointestinal protection. Eur J Pharmacol, 2010, 627: 1-7

72 Wang YP, Wang DH. A novel mechanism contributing to development of Dahl salt-sensitive hypertension-role of the transient receptor potential vanilloid type 1. Hypertension, 2006, 47: 609-614

73 Hao XZ, Chen J, Luo ZD, He H, Yu H, Ma L, Ma S, Zhu T, Liu D, 
Zhu Z. TRPV1 activation prevents high-salt diet-induced nocturnal hypertension in mice. Pflug Arch Eur J Phy, 2011, 461: 345-353

74 Ruiz C, Gutknecht S, Delay E, Kinnamon S. Detection of $\mathrm{NaCl}$ and $\mathrm{KCl}$ in TRPV1 knockout mice. Chem Sens, 2006, 31: 813-820

75 Gao F, Wang DH. Impairment in function and expression of transient receptor potential vanilloid type 4 in Dahl salt-sensitive rats: significance and mechanism. Hypertension, 2010, 55: 1018-1025
76 Fu Y, Subramanya A, Rozansky D, Cohen DM. WNK kinases influence TRPV4 channel function and localization. Am J Physiol Renal Physiol, 2006, 290: F1305-1314

77 Liu DY, Scholze A, Zhu ZM, Kreutz R, Wehland-von-Trebra M, Zidek W, Tepel M. Increased transient receptor potential channel TRPC3 expression in spontaneously hypertensive rats. Am J Hypertens, 2005, 18: 1503-1507

Open Access This article is distributed under the terms of the Creative Commons Attribution License which permits any use, distribution, and reproduction in any medium, provided the original author(s) and source are credited. 